\title{
Evaluation of antioxidant and antimicrobial activity of phenolic lipids produced by the transesterification of 4-hydroxyphenylacetic acid and triglycerides
}

\author{
Mustika Sari ${ }^{1 \dagger}$, Yustine Chung ${ }^{1 \dagger}$, Felicia Agatha ${ }^{1}$ and Hyung Kwoun $\mathrm{Kim}^{2{ }^{*}}$ (D)
}

\begin{abstract}
Several phenolic compounds derived from plant biomass are attracting attention because they display high antioxidant activity. In this study, antioxidant activity was confirmed in 4-hydroxyphenylacetic acid (HPA), and transesterification reaction using Candida antarctica lipase B was performed to enhance the solubility of HPA. The HPA-diolein (HPA-DON) was synthesized from HPA and triolein, while the HPA-fish oil diglyceride (HPA-dFO) was synthesized from HPA and Menhaden fish oil. To increase the conversion yield, the enzyme reaction conditions of the substrate molar ratio, enzyme amount, and reaction time were optimized. After the reaction, HPA-DON and HPA-dFO were purely separated, using prep-LC. The activity assays using DPPH and ABTS radicals confirmed that HPA-DON and HPA-dFO have antioxidant activity. HPA-DON has high activity in non-polar solvents, while HPA-dFO has strong activity in both polar solvents and non-polar solvents. In addition, HPA-dFO has the growth inhibition activity for Bacillus coagulans, Geobacillus stearothermophilus, and Alcaligenes faecalis that cause food spoilage. Therefore, HPA-dFO is a new synthetic substance that has both antioxidant activity and antibacterial activity. The results indicate that these HPA-derivatives can be expected to be developed as important materials in the food and cosmetics industries.
\end{abstract}

Keywords: Lipase, Phenolic lipid, Antioxidant, Antibacterial activity

\section{Introduction}

Widely distributed in plant biomass, phenolic compounds have generated great attention, because of their antioxidant potential [1-3]. As a major subclass of phenolic compounds, phenolic acids are phenols that contain an aromatic ring, and at least one organic carboxylic acid [4]. The antioxidant potential of phenolic acids is given by the reactivity of phenol moiety (hydroxyl) substituent on the aromatic ring [5]. All plant and plant-derived food, such as fruit, vegetables, and grains, contain many phenolic acid compounds. Only a minor fraction of phenolic acid occurs in the free form, one example of which

\footnotetext{
*Correspondence: hkkim@catholic.ac.kr

${ }^{\dagger}$ Mustika Sari and Yustine Chung contributed equally to this work

2 Division of Biotechnology, The Catholic University of Korea,

Bucheon 420-743, Republic of Korea

Full list of author information is available at the end of the article
}

is 4-hydroxyphenylacetic acid (HPA). Previous studies synthesized HPA amides, and evaluated their antioxidant activities. This compound showed radical scavenging activities, and holds promise as antioxidant [6]. Nonetheless, there are many restrictions on the use of phenolic acid in broad application, because many phenolic acids have hydrophilic properties that reduce their solubility in lipophilic media, and also decrease the effectiveness of their antioxidant activity in fat and oil systems [7]. It is important to overcome this limitation, and maintain the bioactive properties of phenolic acid in hydrophobic media.

Menhaden oil is commercially available extracted oil from abundant fish species in the United States [8]. Fish oil is rich in the amount of $\omega-3$ polyunsaturated fatty acids (PUFAs), like eicosapentaenoic acid (EPA) and docosahexaenoic (DHA). EPA and DHA amounts in 
Menhaden oil are around 14-30\% [9]. PUFAs are known to have antibacterial activity against a wide range of bacteria [10-12], which is an important characteristic needed in the food industry to prevent foodborne or food spoilage bacteria growth. However, recent study reported that PUFAs have high susceptibility to lipid oxidation, which limits the practical uses of this compound [13].

Nowadays, one method to prevent or delay auto oxidation in food containing PUFAs is to add antioxidant compound, such as phenolic acid, as an additive, to improve the stabilization of PUFAs [14]. Enzymatic transesterification of phenolic acid with triglyceride or fatty alcohol is gaining interest to increase their solubilization and antioxidant properties in hydrophobic media for extensive industrial application [15-19]. Conjugating phenolic compounds with triglyceride can be performed chemically or enzymatically. However, the use of lipasecatalysed transesterification reaction has been more preferred, because of the mild reaction condition to minimize substrate alteration, high degree of substrate specificity, and positional selectivity [20]. Moreover, enzymatic synthesis in organic media may permit an increase in the solubility of hydrophobic substrates, and also simple recovery of reaction products as further application [21].

In the present study, transesterification reaction of HPA with triolein or fish oil using immobilized Candida antarctica lipase B to produce phenolic lipids was performed. The effects of substrate molar ratio, enzyme amount, and reaction time were investigated. Moreover, the free radical scavenging activity and antibacterial assay of the novel structured phenolic lipids were examined.

\section{Materials and methods Materials}

Candida antarctica lipase B (CalB) immobilized on acrylic resin, 4-hydroxyphenylacetic acid (HPA, 98\%), Menhaden fish oil (FO), triolein (TON), 2,2-diphenyl1-picrylhydrazyl radical (DPPH), 2,2'-azino-bis (3-ethylbenzothiazoline-6-sulphonic acid) (ABTS), potassium persulfate, 2-butanone, 1-butanol, and molecular sieve (4 $\AA$ ) were bought from Sigma-Aldrich (St. Louis, MO, USA). Dichloromethane, dimethylsulfoxide (DMSO), and $\mathrm{n}$-hexane were purchased from Junsei Chemical Co. (Chuo-ku, Tokyo, Japan). Acetic acid was purchased from Kanto Chemical Co. (Chuo-ku, Tokyo, Japan). Ethanol was bought from Merck \& Co. (Darmstadt, Germany). Methanol and 2-propanol were obtained from J.T. Baker (Center Valley, PA, USA). Bacillus coagulans KCTC 3625 and Geobacillus stearothermophilus (KCTC 2107) were purchased from the Korean Collection for Type Cultures (KCTC, Daejeon, Korea), while Alcaligenes faecalis KCCM 40078 was bought from the Korean Culture Center of Microorganisms (KCCM, Seoul, Korea).

\section{Transesterification reaction of HPA with triolein} and Menhaden fish oil

Two transesterification reactions (Scheme 1) were performed, based on the previous literature [22] with several modifications. The first reaction mixture consisted of $40 \mathrm{mM}$ HPA, $240 \mathrm{mM}$ TON, $200 \mathrm{mg}$ molecular sieve, and 1 unit (200 mg) CalB lipase in $10 \mathrm{ml}$ of n-hexane/2butanone mixture $(75: 25, \mathrm{v} / \mathrm{v})$. The reaction mixture was incubated at $35^{\circ} \mathrm{C}$ and $210 \mathrm{rpm}$ for $48 \mathrm{~h}$. The reaction was stopped by removing the lipase from the mixture. The second reaction mixture consisted of $40 \mathrm{mM}$ HPA, $240 \mathrm{mM}$ FO, $200 \mathrm{mg}$ molecular sieve, and 1 unit CalB lipase in $5 \mathrm{ml}$ of a hexane/2-butanone $(85: 15, \mathrm{v} / \mathrm{v})$. The reaction was performed in the same way as the first reaction. After enzyme reaction, reaction media were evaporated in a Speed-Vac system (Eyela, Tokyo, Japan) for $20 \mathrm{~min}$.

\section{HPLC analysis of the reaction products}

The reaction mixtures were dried under vacuum system, and the resulting concentrates were dissolved in isopropanol for HPLC analysis. The concentrated solutions were injected into HPLC systems, and analysed according to the procedure described in the previous literature [16], with slight modification.

HPLC analysis was done using a Cogent C18 e-column (5 $\mu \mathrm{m}, 4.6 \mathrm{~mm} \times 250 \mathrm{~mm}$; MicroSolv Technology Corp., Eatontown, NJ, USA). Elution gradient was conducted with solvent $\mathrm{A}$, made of a mixture of methanol, isopropanol, water, acetic acid (95:5:1:0.5, v/v), and solvent B, consisting of isopropanol at flow rate of $0.9 \mathrm{ml} / \mathrm{min}$. The elution was started by an isocratic flow of $100 \%$ solvent $\mathrm{A}$ for $10 \mathrm{~min}$, followed by a linear gradient to $100 \%$ solvent $\mathrm{B}$ for $20 \mathrm{~min}$, and retained for $5 \mathrm{~min}$. Injected sample volume was $20 \mu \mathrm{l}$, and the detection of reaction components was conducted by UV variable wavelength detector (VWD) at $215 \mathrm{~nm}$. Conversion yield (\%) was calculated based on the decrement of HPA by enzyme reaction using the following Eq. (1).

$$
\text { Conversion yield }(\%)=\frac{A_{H P A, t_{0}}-A_{H P A, t}}{A_{H P A, t_{0}}} \times 100
$$

where $A_{H P A, t_{0}}$ is the peak area of HPA at $0 \mathrm{~h}$; and $A_{H P A, t}$ is the peak area of HPA at a given time $t$.

\section{Purification of HPA-diglycerides}

To obtain a large amount of HPA-diglycerides, the concentrated reaction mixture was dissolved in $5 \mathrm{ml}$ isopropanol, and injected into preparative LC (Prep-LC) column. The Prep-LC was performed with an XBridge BEH C18 OBD Prep column $(5 \mu \mathrm{m}, 50 \mathrm{~mm} \times 250 \mathrm{~mm}$, 

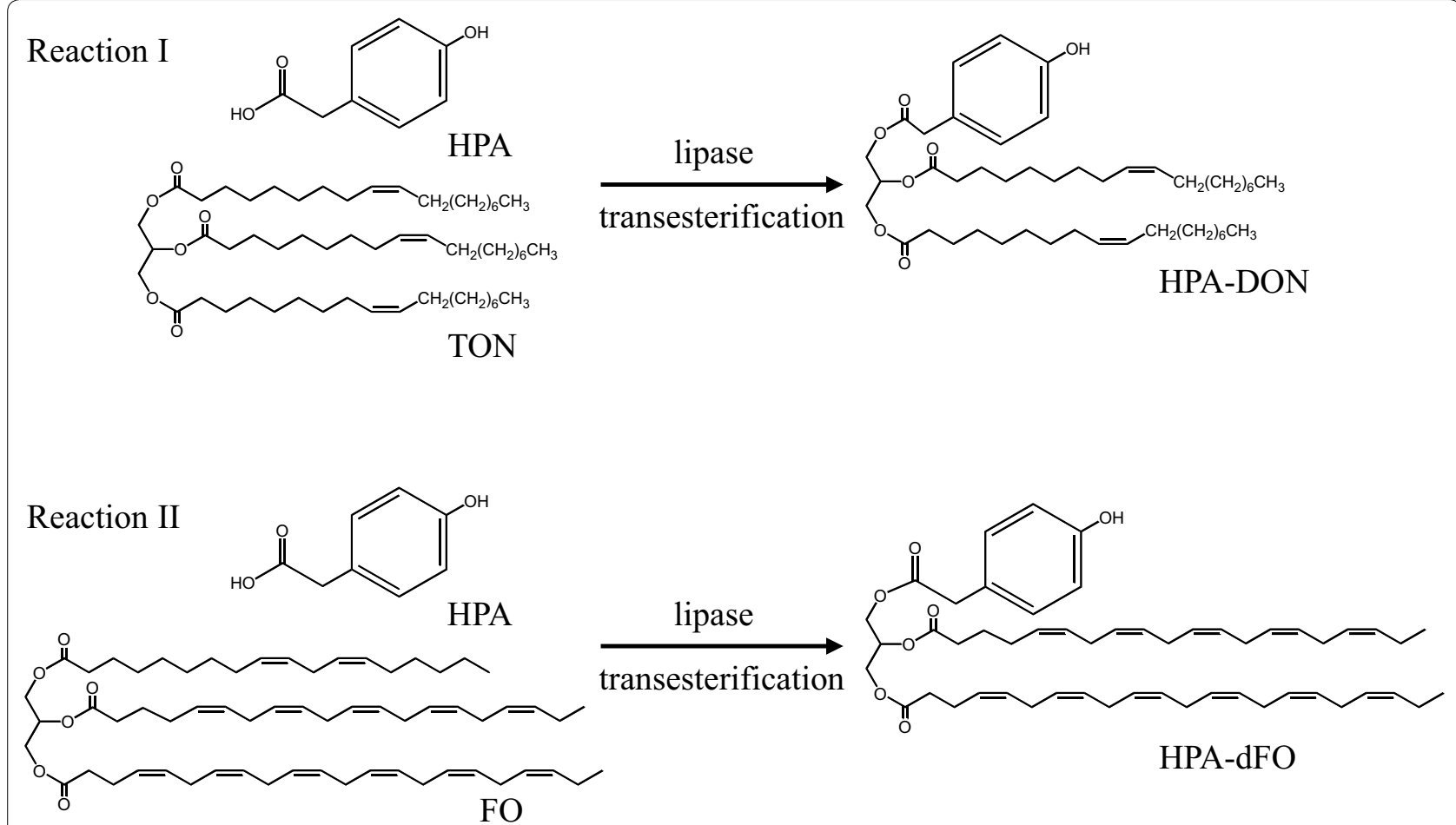

Scheme 1 CalB lipase-mediated transesterification using HPA with triolein (Reaction I) or Menhaden fish oil (Reaction II). HPA, 4-hydroxyphenylacetic acid; TON, triolein; HPA-DON, HPA-diolein; FO, Menhaden fish oil; HPA-dFO, HPA-fish oil diglyceride; CalB, Candida antarctica lipase B

Waters, Milford, MA, USA) in the same elution condition as the HPLC analysis system. Flow rate was $55 \mathrm{ml} /$ min, and the detection of reaction components was performed by UV detector at $215 \mathrm{~nm}$. The fraction eluting between 8 and $20 \mathrm{~min}$ was collected, and concentrated using rotary evaporator (EYELA N1000V, Tokyo, Japan), to yield a viscous, yellow oily liquid. Then the purified HPA-diglycerides were weighed to obtain product molar concentration.

\section{Determination of the radical scavenging activity of HPA-diglycerides}

The radical scavenging activities of HPA, HPA-DON, and HPA-dFO were evaluated by DPPH assay [23, 24]. The DPPH assay was performed with freshly prepared $0.4 \mathrm{M}$ DPPH stock solution in methanol, 1-butanol, dichloromethane, and hexane. The $10 \mathrm{mM}$ of reaction products and HPA were mixed with DPPH radical solution $(50 \mathrm{mM})$ in the same organic solvent, and incubated in the dark at room temperature (RT). DPPH radical reduction was monitored spectrophotometrically at $517 \mathrm{~nm}$ for $30 \mathrm{~min}$ at $5 \mathrm{~min}$ interval. The residual DPPH radical percentage was calculated as the following Eq. (2):

$$
\text { Residual DPPH radical }(\%)=\frac{A_{517} \text { of sample }}{A_{517} \text { of control }} \times 100
$$

where $\mathrm{A}_{517}$ is the absorbance at $517 \mathrm{~nm}$; and control contains $250 \mu \mathrm{l}$ of solvent, instead of HPA or HPA-diglycerides.

The radical scavenging activity of HPA, HPA-DON, and HPA-dFO was also assessed by ABTS assay. The ABTS assay was performed using the ABTS radical cation solution $\left(\mathrm{ABTS}^{\bullet+}\right)$. $\mathrm{ABTS}^{\bullet+}$ solution was produced by reacting a $7 \mathrm{mM}$ ABTS stock solution with $2.45 \mathrm{mM}$ potassium persulfate $(1: 1, \mathrm{v} / \mathrm{v})$ in the dark room at RT for $16 \mathrm{~h}$ before use. ABTS $^{\bullet+}$ solution was diluted with methanol or a DMSO/dichloromethane mixture $(2: 8, \mathrm{v} / \mathrm{v})$, to obtain the starting absorbance of 0.77 at $734 \mathrm{~nm}$. Then, $100 \mu \mathrm{l}$ of $3 \mathrm{mM}$ HPA or HPA-diglycerides in isopropanol was mixed with $900 \mu \mathrm{lBCS}^{\bullet+}$ solution, and incubated at RT for $20 \mathrm{~min}$. The absorbance was measured at $734 \mathrm{~nm}$ at 5 min interval, to detect the decrease of absorbance. Radical scavenging activity was expressed as a percentage of residual $\mathrm{ABTS}^{\bullet+}$ radicals as the following Eq. (3).

$$
\text { Residual ABTS radical (\%) }=\frac{A_{734} \text { of sample }}{A_{734} \text { of control }} \times 100
$$

where $\mathrm{A}_{734}$ is the absorbance at $734 \mathrm{~nm}$; and control contains $100 \mu \mathrm{l}$ of solvent, instead of HPA or HPA-diglycerides. 


\section{Determination of the antibacterial activity of HPA-diglycerides}

The antibacterial activities of HPA and HPA-diglycerides against three food spoilage bacteria (Alcaligenes faecalis, Bacillus coagulans, and Geobacillus stearothermophilus) were measured as follows: serial dilution of HPA and HPA-diglycerides in ethanol was dissolved in $4 \mathrm{ml}$ LuriaBertani (LB) medium (1\% tryptone, $0.5 \%$ yeast extract, and $1 \%$ sodium chloride), to achieve final concentration of 31.25-1000 $\mu \mathrm{M}$. A. faecalis and B. coagulans were cultured at $37^{\circ} \mathrm{C}$ and G. stearothermophilus at $55{ }^{\circ} \mathrm{C}$, until they reached the optical density of 0.6 at $600 \mathrm{~nm}$. The cultured inoculums were then added into all assay tubes to give an initial concentration of approximately $5 \times 10^{5}$ $\mathrm{CFU} / \mathrm{ml}$ and were incubated at their optimum temperatures. After incubation, the antibacterial activity was determined by measuring the absorbance at $600 \mathrm{~nm}$. A $1 \%$ ethanol in LB medium was used as a negative control.

\section{Results and discussion}

Transesterification of HPA with triglycerides

CalB-mediated transesterification reactions were performed using HPA with TON or FO (Scheme 1). We used HPA and FO to optimize the transesterification reaction conditions. First, the effect of substrate molar ratio on the transesterification reaction was examined. HPA concentration was fixed at $40 \mathrm{mM}$, while FO concentration was changed from 40 to $240 \mathrm{mM}$. Figure 1a shows the conversion yields by transesterification reactions using various molar ratios of substrates. Increasing FO concentration led to higher conversion yield. Using a molar ratio of $1: 6$, the highest conversion yield of $56 \%$ was obtained. Therefore, $40 \mathrm{mM} \mathrm{HPA}$ and $240 \mathrm{mM}$ FO were used for further experiments. Second, the enzyme amount needed to obtain maximum conversion yield was investigated using various amount of CalB enzymes. Figure $1 \mathrm{~b}$ shows that the conversion yield increased when the enzyme amount increased. The maximum conversion yield of $65.5 \%$ was achieved using $200 \mathrm{mg}$ CalB. Higher amount $(400 \mathrm{mg})$ of $\mathrm{CalB}$ rather reduced conversion yield, which might be related to the diffusional limitation of substrates. Based on this experimental result, $200 \mathrm{mg}$ of CalB was used in the subsequent experiment. The final optimized reaction mixture was as follows. $40 \mathrm{mM}$ HPA, $240 \mathrm{mM}$ FO, $200 \mathrm{mg} \mathrm{CalB}$, and $200 \mathrm{mg}$ molecular sieve in $5 \mathrm{ml}$ hexane/2-butanone $(85: 15, \mathrm{v} / \mathrm{v})$. For CalB-mediated transesterification reaction using HPA and TON, we adopted a similar reaction condition: $40 \mathrm{mM} \mathrm{HPA}$, $240 \mathrm{mM}$ TON, $200 \mathrm{mg}$ CalB, and $200 \mathrm{mg}$ molecular sieve in $10 \mathrm{ml}$ hexane/2-butanone $(75: 25, \mathrm{v} / \mathrm{v})$.

Using the above mentioned-reaction systems, conversion yields were monitored with time course (Fig. 1c).

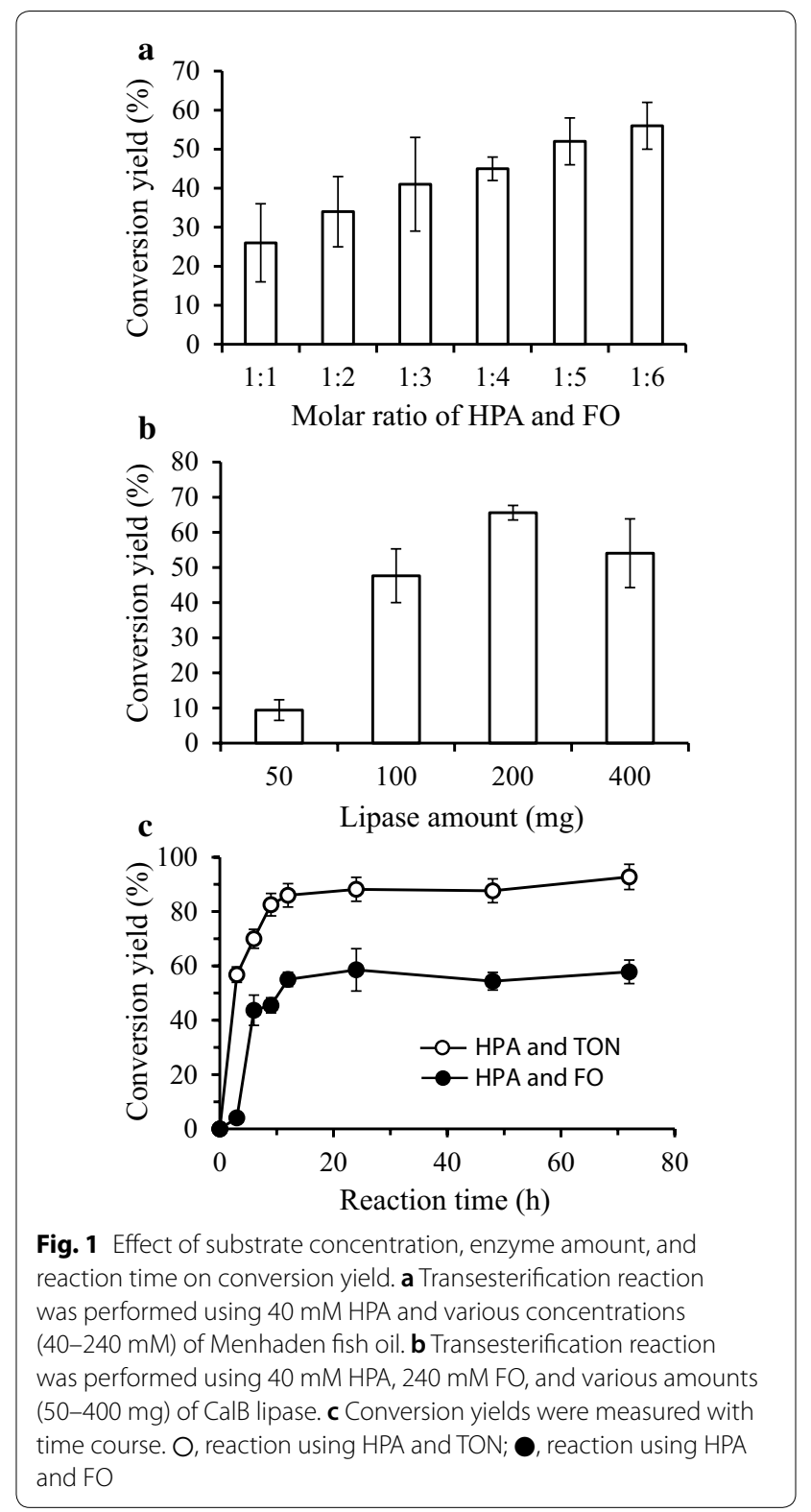

Conversion yields increased until $24 \mathrm{~h}$, and the highest conversion yields obtained were $87 \%$ and $59 \%$ for HPADON and HPA-dFO, respectively. After $24 \mathrm{~h}$, conversion yields were kept steady up to $72 \mathrm{~h}$. These results implied that as the forward reaction using HPA and triglyceride progressed, fatty acids accumulated, and reverse reaction using HPA-diglyceride and fatty acid started. The forward reaction rate and reverse reaction rate became the same speed at $24 \mathrm{~h}$. The difference in final conversion yields between the reaction I and II seemed to be related to the difference in equilibrium constants of the two reactions. 


\section{HPLC analysis of the reaction products and purification of HPA-diglycerides}

The reaction products produced by CalB-mediated transesterification were analysed using HPLC system. First, $0 \mathrm{~h}$ reaction mixtures showed HPA, TON (or FO) peaks, as in Fig. 2a, d. The first peak (RT 2.9 min) was identified as HPA. TON peak and FO peaks appeared at RT 28.9-30.4 min and RT 20.8-29.1 min, respectively. The FO peaks were composed of many sub-peaks, due to the various fatty acid compositions of Menhaden oil.

Second, the $24 \mathrm{~h}$ reaction mixture from HPA:TON showed that the HPA peak became reduced in size, and new major peaks at RT 18.2-21.9 min were produced (Fig. 2b). That from HPA:FO showed that the HPA peak was also reduced in size, and many peaks at RT 8-18.6 min were made (Fig. 2e). By comparison with other chromatograms from the previous literature, new peaks produced by enzyme reactions were annotated as HPA-DON and HPA-dFO, respectively [17]. These reaction products were collected using Prep-LC system as shown in Fig. 2c and f, and concentrated for further study.

\section{Evaluation of DPPH radical scavenging activity}

The antioxidant activity of HPA-DON and HPA-dFO was investigated on the basis of their scavenging activity of DPPH radical. Figure 3 shows the DPPH assay results in the presence of various solvents, including methanol ( $\log \mathrm{P},-0.74), 1$-butanol ( $\log \mathrm{P}, 0.836)$, dichloromethane ( $\log \mathrm{P}, 1.25)$, and hexane (logP, 4.66).

First, in methanol system, HPA-DON showed weak scavenging activity (18.2\% after $30 \mathrm{~min})$, whereas HPA$\mathrm{dFO}$ showed very strong scavenging activity (almost $100 \%$ after $15 \mathrm{~min}$ ) (Fig. 3a, b). Therefore, HPA-dFO showed quite stronger antioxidant activity than HPADON and HPA in methanol system. It is known that the DPPH radical scavenging activity of a compound depends on the type of solvent [17]. To elucidate the relationship between the radical scavenging activity of HPA, HPA-DON, and HPA-dFO and the hydrophobic properties of solvents, DPPH assays were also performed in non-polar solvents. In 1-butanol system, HPA and HPA-DON scavenged $20.43 \%$ and $5.89 \%$ of DPPH radicals, respectively, whereas HPA-dFO showed somewhat stronger scavenging activity of $52 \%$ (Fig. 3c, d). The radical scavenging activity of HPA could not be assayed in dichloromethane and hexane systems, due to its very low

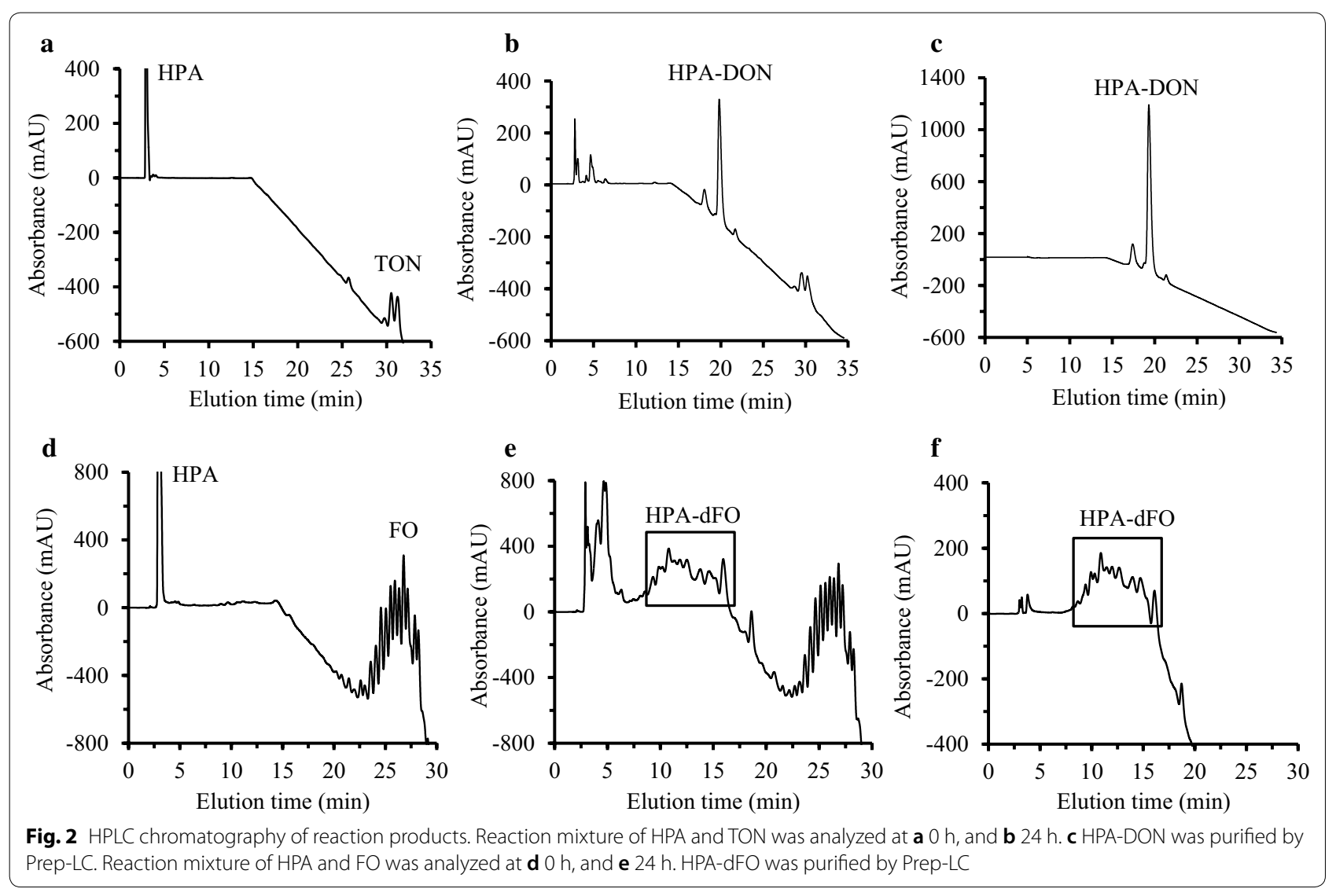




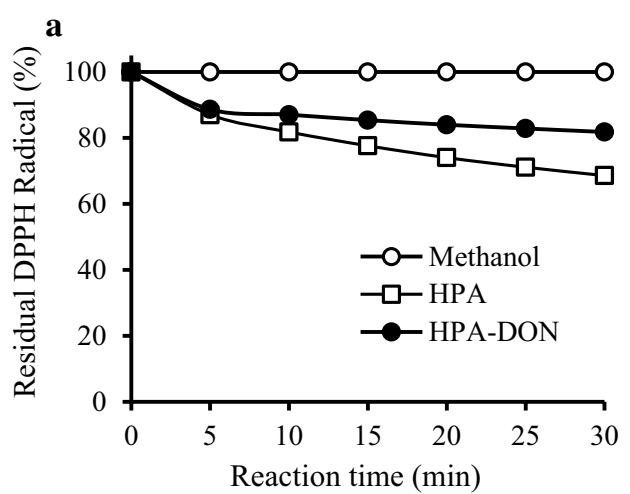

$\mathbf{b}$
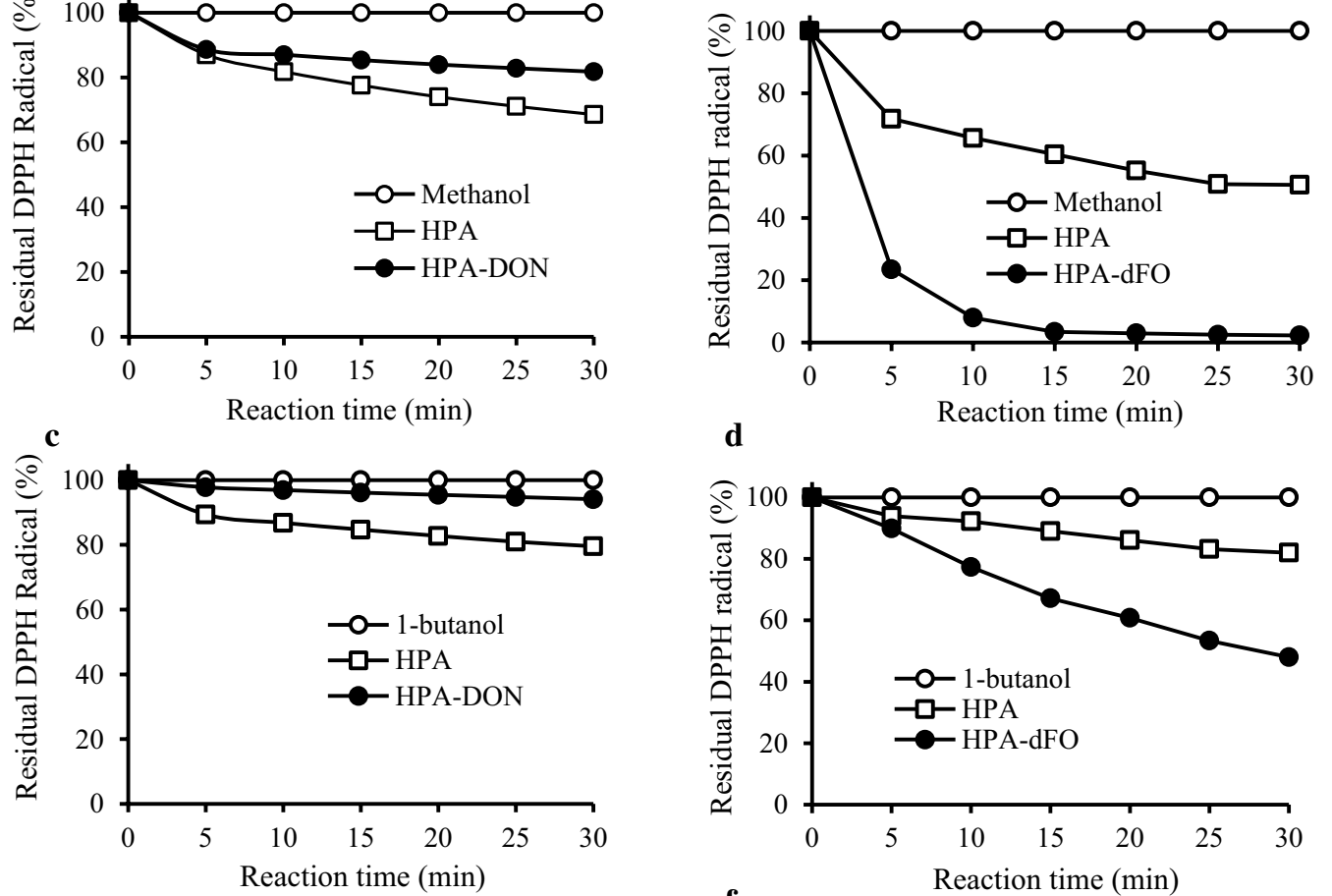

d
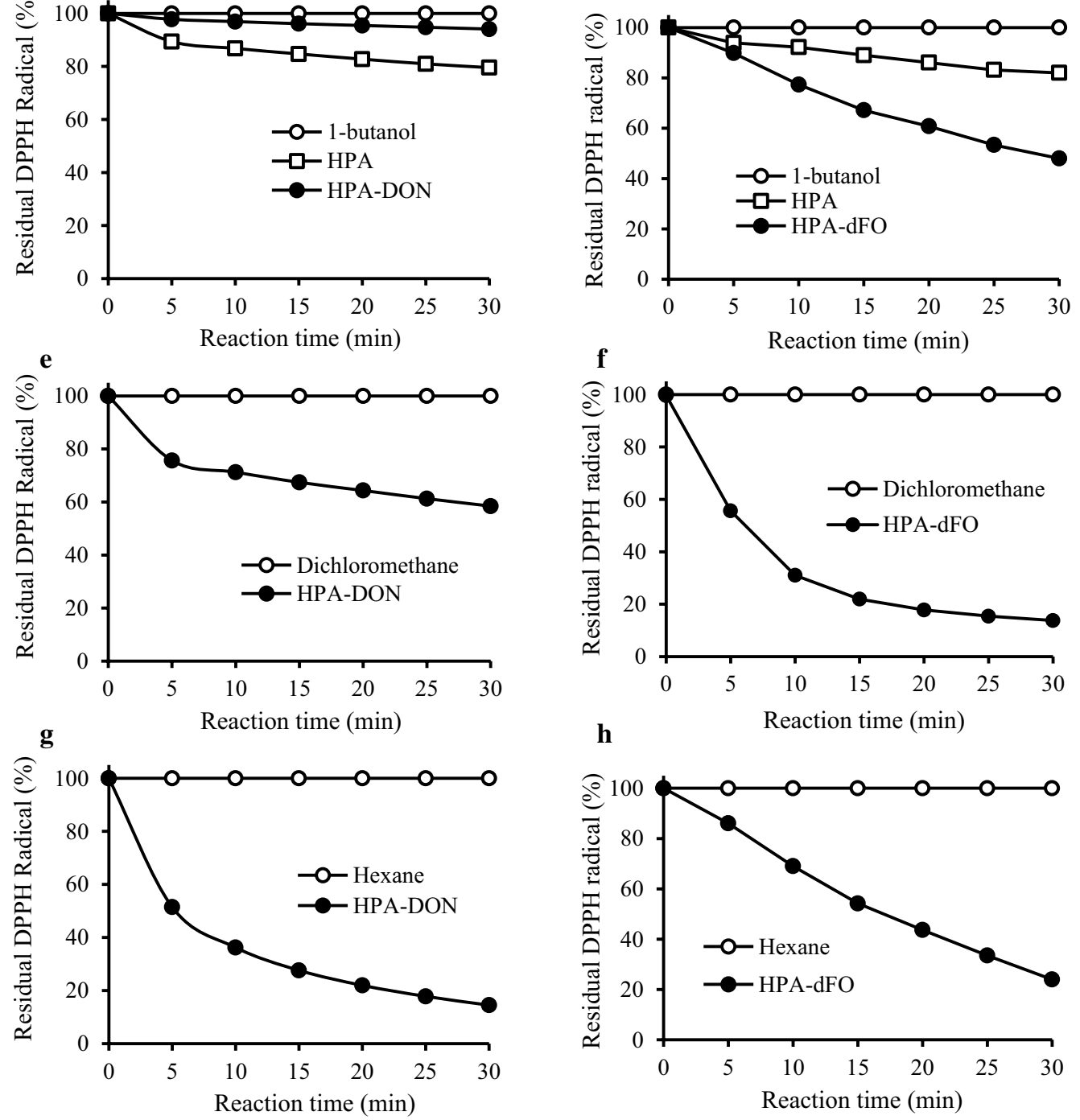

Fig. 3 DPPH radical scavenging using HPA-DON and HPA-dFO. DPPH radical scavenging activity was measured using HPA-DON (left column) and HPA-dFO (right column). Assay was performed in $\mathbf{a}$ and $\mathbf{b}$ methanol, $\mathbf{c}$ and $\mathbf{d}$ 1-butanol, e and $\mathbf{f}$ dichloromethane, and $\mathbf{g}$ and $\mathbf{h}$ hexane systems, using each solvent, (O), $10 \mathrm{mM} \mathrm{HPA}(\square)$, and 10 mM HPA-DON (or HPA-dFO) (0) 
solubility in those solvents. However, in dichloromethane system, HPA-DON and HPA-dFO scavenged $41.53 \%$ and $87 \%$ of radicals, respectively (Fig. 3e, f). In hexane system, HPA-DON and HPA-dFO also showed strong scavenging activity of $85.49 \%$ and $77 \%$, respectively (Fig. $3 \mathrm{~g}, \mathrm{~h}$ ).

These results demonstrate that the hydrophobic properties of solvents have a profound impact on the radical scavenging activity of HPA derivatives; while HPA showed some radical scavenging activity only in polar solvent, HPA-DON showed a great deal of radical scavenging activity in nonpolar solvents, and HPA-dFO showed a quite strong radical scavenging activity in polar solvent, as well as nonpolar solvents.

\section{Evaluation of ABTS radical scavenging activity}

The antioxidant activity of HPA-DON and HPA-dFO was also investigated on the basis of their scavenging activity of ABTS radical. ABTS cation radical $\left(\mathrm{ABTS}^{*+}\right)$ was generated when ABTS salt was reacted with potassium persulfate, and reduction of ABTS radical was measured by the colour change in $734 \mathrm{~nm}$ [24]. Figure 4 shows that the ABTS assay was performed in two solvent systems, including methanol ( $\log \mathrm{P},-0.74)$ and DMSO:dichloromethane $(2: 8, \quad \mathrm{v} / \mathrm{v}) \quad(\log P, \quad 0.45)$. In methanol system, HPA-DON and HPA-dFO scavenged $72.2 \%$ and $73.9 \%$ after 20 min, respectively (Fig. 4a, b). In DMSO:dichloromethane (2:8, v/v) system, HPA-DON and HPA-dFO scavenged $40.3 \%$ and $51.1 \%$ after $20 \mathrm{~min}$, respectively (Fig. 4c, d). These results implied that HPA and HPA derivatives showed ABTS radical scavenging activity in both solvents, and although the activity was relatively large in methanol solvent, the activity difference according to solvent system was not greater than expected.

\section{Antibacterial activity assay of HPA-diglycerides}

The antibacterial assay of HPA derivatives was performed with three bacterial strains of Bacillus coagulans, Alcaligenes faecalis, and Geobacillus stearothermophilus. These bacteria were chosen as target microorganisms for the following reasons. B. coagulans is frequently found in acidified food with $\mathrm{pH}$ values ranging 4-4.5, causing flat
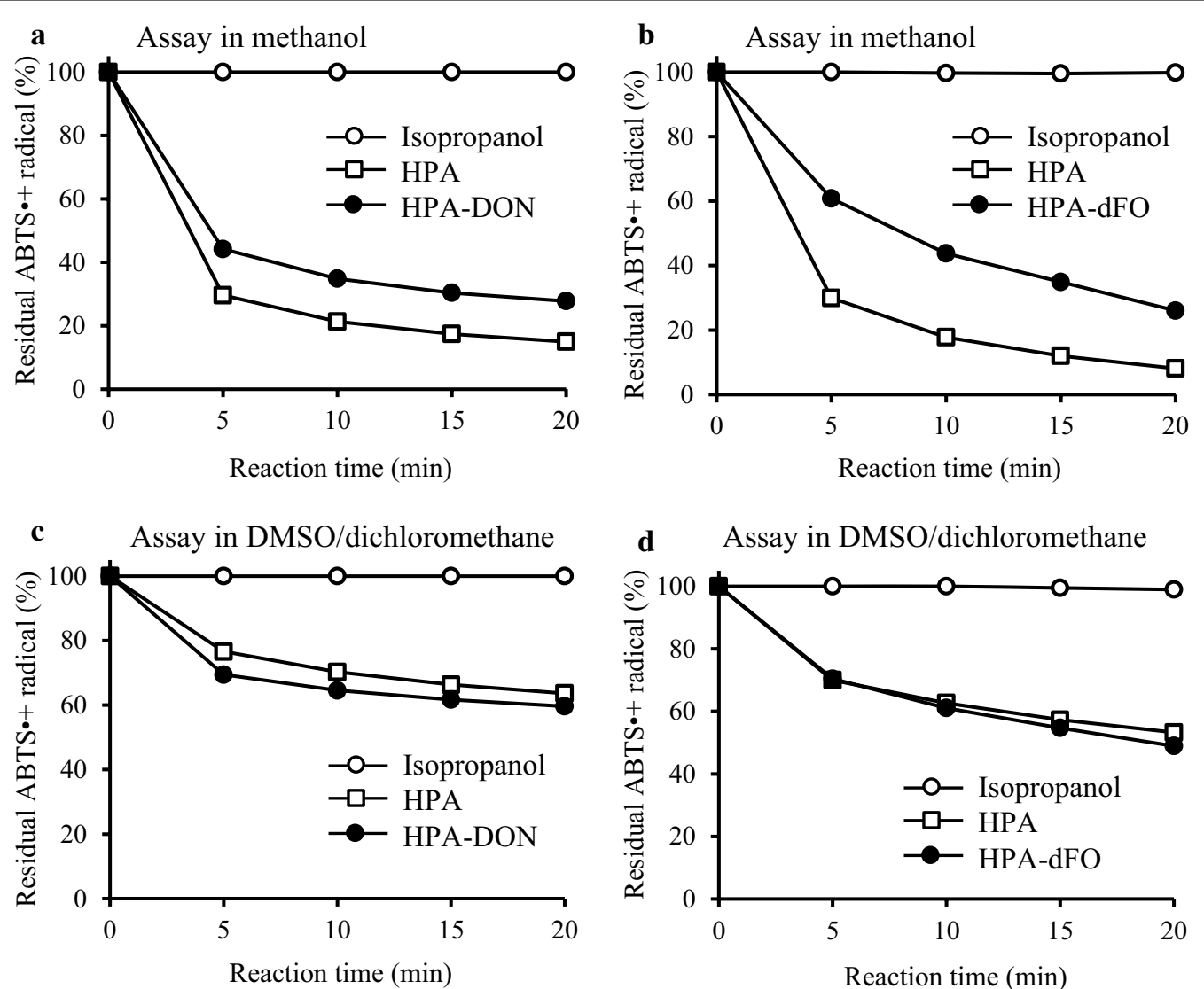

Fig. $4 \mathrm{ABTS}^{*+}$ radical scavenging using HPA-DON and HPA-dFO. ABTS ${ }^{+}$radical scavenging activity was measured using HPA-DON (left column), and HPA-dFO (right column). Assay was performed in a and $\mathbf{b}$ methanol, and $\mathbf{c}$ and $\mathbf{d} \mathrm{DMSO} /$ dichloromethane (2:8. v/v) systems, using isopropanol (O), 10 mM HPA ( $\square$ ), and 10 mM HPA-DON (or HPA-dFO) (O) 
Table 1 Antibacterial activity of HPA-DON and HPA-dFO

\begin{tabular}{llll}
\hline Bacterial strain & \multicolumn{3}{l}{ MIC $(\boldsymbol{\mu M})$} \\
\cline { 2 - 4 } & HPA & HPA-DON & $\begin{array}{l}\text { HPA- } \\
\mathbf{d F O}\end{array}$ \\
\hline Bacillus coagulans KCCM11715 & $>1000>1000$ & 250 \\
Alcaligens faecalis KCTC2678 & $>1000>1000$ & 250 \\
$\begin{array}{l}\text { Geobacillus stearothermophilus } \\
\text { KCCM12147 }\end{array}$ & $>1000>1000$ & 1000 \\
\hline
\end{tabular}

MIC (Minimum Inhibitory Concentration) was calculated by $80 \%$ growth inhibition of control bacterial growth

sour spoilage [25]. A. faecalis is a food-borne opportunist, and contaminates medical devices, leading to infection in blood [26-28]. G. stearothermophilus causes spoilage in processed food, such as canned foods and evaporated milk [29-31].

HPA-DON and HPA-dFO were dissolved in ethanol, and added into bacterial cell culture with $1 \%(\mathrm{v} / \mathrm{v})$ volume. Table 1 shows that HPA-DON did not show any bacterial inhibition activity against any of the bacterial strains. HPA-dFO has certain antibacterial activity towards all bacterial strains. The highest inhibition was observed with B. coagulans and A. faecalis at $250 \mu \mathrm{M}$ concentration. HPA-dFO strongly inhibited the cell growth of G. stearothermophilus at $1000 \mu \mathrm{M}$. It was already expected that HPA-dFO has antibacterial activity, for Menhaden fish oil has a large amount of PUFAs, which have anti-bacterial activity.

Taken together, we synthesized HPA-DON and HPAdFO by transesterification reactions. HPA-DON has antioxidant activity in non-polar solvents, whereas HPA$\mathrm{dFO}$ has antioxidant activity in polar solvent, as well as non-polar solvents. Moreover, HPA-dFO also showed antibacterial activity towards some food spoilage bacteria, including B. coagulans, A. faecalis, and G. stearothermophilus. These HPA-derivatives may be expected to be used as important biomaterials in the food and cosmetics industries.

\section{Authors' contributions}

MS and YC carried out the enzymatic reaction and characterized the HPA-dFO. FA carried out the enzymatic reaction and characterized the HPA-DON. HKK carried out the enzymatic reaction and drafted the manuscript. All authors read and approved the final manuscript.

\begin{abstract}
Author details
${ }^{1}$ Faculty of Biotechnology, Atma Jaya Catholic University of Indonesia, Jalan Jenderal Sudirman 51, Jakarta Selatan 12930, Indonesia. ${ }^{2}$ Division of Biotechnology, The Catholic University of Korea, Bucheon 420-743, Republic of Korea.
\end{abstract}

\section{Acknowledgements}

This work was supported by Korea Polar Research Institute (PE18100). This research was supported by Basic Science Research Program through the National Research Foundation of Korea (NRF) funded by the Ministry of Education (NRF-2018R1D1A1B07047529).

\section{Competing interests}

The author declares that they have no competing interests.

\section{Publisher's Note}

Springer Nature remains neutral with regard to jurisdictional claims in published maps and institutional affiliations.

Received: 27 December 2018 Accepted: 7 February 2019

Published online: 25 February 2019

\section{References}

1. Matilla P, Hellstrom J, Torronen R (2006) Phenolic acids in berries, fruits, and beverages. J Agric Food Chem 54:7193-7199

2. Shahidi F, Ambigaipalan P (2015) Phenolics and polyphenolics in foods, beverages and spices: antioxidant activity and health effects - a review. J Func Foods 18:820-897

3. Sevgi K, Tepe B, Sarikurkcu C (2015) Antioxidant and DNA damage protection potentials of selected phenolic acids. Food Chem Toxicol 77:12-21

4. Goleniowski M, Bonfill M, Cusido R, Palazón J (2013) Phenolic acids. In: Ramawat GK, Mérillon JM (eds) Natural products: phytochemistry, botany and metabolism of alkaloids, phenolics and terpenes. Springer, Berlin, pp 1951-1973

5. Kim YJ (2007) Antimelanogenic and antioxidant properties of gallic acid. Biol Pharm Bull 30:1052-1055

6. Jung YS, Kang TS, Yoon JH, Joe BY, Lim HJ, Seong CM, Park WK, Kong JY, Cho J, Park NS (2002) Synthesis and evaluation of 4-hydroxyphenylacetic acid amides and 4-hydroxycinnamamides as antioxidants. Bioorg Med Chem Lett 12:2599-2602

7. Stamatis H, Sereti V, Kolisis FN (2001) Enzymatic synthesis of hydrophilic and hydrophobic derivatives of natural phenolic acids in organic media. J Mol Cat B Enzyme 11:323-328

8. Yin H, Sathivel S (2010) Physical properties and oxidation rates of unrefined Menhaden oil (Brevoortia patronus). J Food Sci 75:E163-E168

9. Yamaguchi I, Akoh CC, Lai OM (2004) Modification of fish oil by lipozyme TL IM to produce structured lipid. J Food Lipids 11:65-73

10. Desbois AP, Lawlor KC (2013) Antibacterial activity of long-chain polyunsaturated fatty acids against Propionibacterium acnes and Staphylococcus aureus. Mar Drugs 11:4544-4557

11. Chitra SR, Radhakrishnan CK (2011) Antibacterial activities of polyunsaturated fatty acid extracts from Sardinella longiceps and Sardinella fimbriata. Indian J Geo-Mar Sci 40:710-716

12. Huang CB, Ebersole JL (2010) A novel bioactivity of omega-3 polyunsaturated fatty acids and their ester derivatives. Mol Oral Microbiol 25:75-80

13. Tao $L$ (2015) Oxidation of polyunsaturated fatty acids and its impact on food quality and human health. Adv Food Tech Nutri Sci 1:135-142

14. Lee S, Faustman C, Djordjevic D, Faraji H, Decker EA (2006) Effect of antioxidants on stabilization of meat products fortified with $\mathrm{n}-3$ fatty acids. Meat Sci 72:18-24

15. Figueroa-Espinoza MC, Villeneuve P (2005) Phenolic acid enzymatic lipophilization. J Agric Food Chem 53:2779-27787

16. Karboune S, Safari M, Lue BM, Yeboah FK, Kermasha S (2005) Lipase-catalyzed biosynthesis of cinnamoylated lipids in a selected organic solvent medium. J Biotechnol 119:281-290

17. Natalia A, Kim SJ, Kim HK (2016) Antioxidant and antibacterial activity of fatty acid vanillyl ester produced by Proteus vulgaris K80 lipase-mediated transesterification. J Mol Cat B Enzym 133:475-481

18. Sabally K, Karboune S, St-Louis R, Kermasha S (2007) Lipase-catalyzed synthesis of phenolic lipids from fish liver oil and dihydrocaffeic acid. Biocatal Biotransform 25:211-218

19. Stamatis H, Sereti V, Kolisis FN (2001) Enzymatic synthesis of hydrophilic and hydrophobic derivatives of natural phenolic acids in organic media. J Mol Catal B Enzyme 11:323-328

20. Kirk O, Christensen MW (2002) Lipases from Candida antarctica: unique biocatalysts from a unique origin. Org Proc Res Dev 6:446-451

21. Stevenson DE, Parkar SG, Zhang JL, Stanley RA, Jensen DJ, Cooney JM (2007) Combinatorial enzymatic synthesis from functional testing of phenolic acid esters catalyzed by Candida antartica lipase B (Novozym 435 ${ }^{\circledR}$ ). Enzyme Microbiol Technol 40:1078-1086 
22. Jo JC, Kim HK (2016) Production of cinnamoyl lipids using immobilized Proteus vulgaris K80 lipase and an evaluation of their antioxidant activity. J Mol Cat B Enzym 129:54-60

23. Floegel A, Kim DO, Chung SJ, Koo SI, Chun OK (2011) Comparison of ABTS/DPPH assays to measure antioxidant capacity in popular antioxidant-rich US foods. J Food Compos Anal 24:1043-1048

24. Shalaby EA, Shanab SMM (2013) Comparison of DPPH and ABTS assays for determining antioxidant potential of water and methanol extracts of Spirulina platensis. Indian J Geo-Mar Sci 42:556-564

25. Haberbeck LU, da Silva Riehl CA, Salamão BC, Aragão GM (2012) Bacillus coagulans spore inactivaction through the application of oregano essential oil and heat. LWT Food Sci Technol 46:267-273

26. Ethica SN, Semiarti E, Widada J, Oedijono O, Raharjo TJ (2017) Characterization of moaC and a nontarget gene fragments of food-borne pathogen Alcaligenes sp. JG3 using degenerate colony and arbitrary PCRs. J Food Saf 1:1. https://doi.org/10.1111/jfs.12345
27. Kahveci A, Asicioglu E, Tigen E, Ari E, Arikan H, Odabasi Z, Ozener C (2011) Unusual causes of peritonitis in a peritoneal dialysis patient: Alcaligenes faecalis and Pantoea agglomerans. Ann Clin Microbiol Antimicrob 10:12

28. Mondo MA, Padilla-Zakour OI, Worobo RW (2004) Growth inhibition of foodborne pathogens and food spoilage organisms by select raw honeys. Int J Food Microbiol 97:1-8

29. Durand L, Planchon S, Guinebretiere MH, Carlin F, Remize F (2015) Genotypic and phenotypic characterization of foodborne Geobacillus stearothermophilus. Food Microbiol 45:103-110

30. Kakagianni M, Gougouli M, Koutsoumanis KP (2016) Development and application of Geobacillus stearothermophilus growth model for predicting spoilage of evaporated milk. Food Microbiol 57:28-35

31. Rigaux C, André S, Albert I, Carlin F (2014) Quantitative assessment of the risk of microbial spoilage in foods. Prediction of non-stability at $55^{\circ} \mathrm{C}$ caused by Geobacillus stearothermophilus in canned green beans. Int J Food Microbiol 171:119-128

\section{Submit your manuscript to a SpringerOpen ${ }^{\odot}$ journal and benefit from:}

- Convenient online submission

- Rigorous peer review

- Open access: articles freely available online

- High visibility within the field

- Retaining the copyright to your article

Submit your next manuscript at $\gg$ springeropen.com 